\title{
Colonization and successional patterns of the mobile epifaunal community along an environmental gradient in a marine cave
}

\author{
Carlos Navarro-Barranco ${ }^{1, *}$, José Manuel Guerra-García ${ }^{1}$, Luis Sánchez-Tocino ${ }^{2}$, \\ Macarena Ros $^{1}{ }^{1}$, Marta Florido ${ }^{1}$, José Carlos García-Gómez ${ }^{1}$ \\ ${ }^{1}$ Laboratorio de Biología Marina, Departamento Zoología, Facultad de Biología, Universidad de Sevilla, \\ Avda Reina Mercedes 6, 41012 Sevilla, Spain \\ ${ }^{2}$ Departamento de Biología Animal, Facultad de Ciencias, Universidad de Granada, Campus Universitario de Fuentenueva, \\ s/n., 18071 Granada, Spain
}

\begin{abstract}
In spite of the high importance of mobile epifauna in all marine habitats, their patterns of colonization and succession in marine caves have not been studied until now. In the present study, we used artificial substrates deployed at 4 positions along an environmental gradient of a $\sim 100 \mathrm{~m}$ long cave system, and retrieved at different times $(1.5,3$ and $6 \mathrm{mo})$, to explore the changes in abundance, species richness, and community structure of the epifauna. All inner cave stations showed significantly lower species richness and abundance. Despite different dispersal modes, the dominant species detected were able to quickly $(<1.5 \mathrm{mo})$ colonize the inner parts of the cave, yet their abundances were significantly higher outside the cave throughout the whole study. This suggests that environmental factors such as trophic supply or light intensity, rather than isolation, are probably the main factors responsible for the observed differences among cave positions. We also detected a gradient in the rate of community development, with communities outside the cave developing much earlier than those situated in the innermost parts. Finally, high temporal stability of communities was observed within the cave, which is likely related to more stable environmental conditions - a hypothesis supported by our detection of a dampening of the thermal oscillations within the cave. The low rates of community development and turnover observed inside marine caves supports the consideration of these habitats being very sensitive to natural and human-induced environmental disturbances, and hence a top priority for conservation.
\end{abstract}

KEY WORDS: Marine caves · Benthic ecology · Epifauna · Amphipoda · Mediterranean Sea Resale or republication not permitted without written consent of the publisher

\section{INTRODUCTION}

Colonization and succession processes have a fundamental importance in marine ecosystems and much effort has been devoted to their study in recent decades (Antoniadou et al. 2010). However, their patterns and mechanisms are not clearly understood, since colonization and ecological succession can be unpredictable processes driven by many, highly stochastic factors (Sutherland 1974,
Chapman 2007, Pacheco et al. 2010). Moreover, the interaction among these factors and their relative importance is complex and variable, hence requiring system-specific evaluations (Zajac et al. 1998, Pacheco et al. 2010). In this sense, most studies have primarily focused on large components of intertidal and shallow communities, while the less accessible biota (i.e. cryptic or mobile organisms) and habitats (i.e. deep communities, marine caves) remain poorly studied (Olabarria 
2002, Underwood \& Chapman 2006, Antoniadou et al. 2010).

Marine cave communities have been described as inhabiting environments very sensitive to natural and human disturbances, and as such are protected by the European Community (Habitat Directive 92/43 EEC). Understanding the mechanisms and rates of ecological succession in these habitats is mandatory to predict their recovery patterns after disturbance events. Recruitment limitation is an important factor determining the structure and dynamics of all benthic communities, but its influence in marine caves has been considered to be even stronger (Zabala et al. 1989, Fraschetti et al. 2002). Marine caves are often characterized by an impoverishment of their benthic communities, which has been traditionally associated with their oligotrophic and isolated conditions (Zabala et al. 1989, Harmelin 1997). In spite of this, to date the settlement and primary successional patterns in marine caves have only been studied for sessile organisms (Denitto et al. 2007). Mobile invertebrates constitute a diverse group within marine cave fauna (Navarro-Barranco et al. 2013, 2014) and it could be expected that the magnitude of the recruitment limitation and their successional processes may differ from those observed in sessile organisms. Actively swimming animals, such as crustaceans, exhibit more dynamic populations, higher turnover rates, and can quickly colonize new habitats (Virnstein \& Curran 1986, Taylor 1998, Poore 2005). On the other hand, unlike most sessile organisms (which produce planktonic larvae) a high proportion of mobile epifauna is composed of organisms with direct development (i.e. amphipods, isopods or tanaids) that disperse directly as juveniles and adults by floating in the water column, rafting on biotic and abiotic substrata, and also by active swimming or crawling from host to host (Taylor 1998, Thiel 2003, Havermans et al. 2007).

In this study, we compared the patterns of colonization and succession by mobile epifauna in artificial substrates, deployed at different positions within a marine cave. The use of artificial substrates limits the extrapolation of our conclusions to the natural environment. However, this is a valuable approach to evaluate colonization and successional processes in different habitats since they provide substrates of uniform size, complexity and history, thereby minimizing uncontrollable variation among replicates (Underwood \& Chapman 2006, Chapman 2007, Tuya et al. 2009, García-Sanz et al. 2012).

Many of the physical and biotic factors (such as hydrodynamism, temperature, light or competition intensity) that present marked gradients inside marine caves have been proved to modulate the colonization and successional pathways of epifaunal communities (Eggleston et al. 1999, Tanaka \& Leite 2004, Poore 2005, Havermans et al. 2007). Therefore, the main objective of the present study was to test the hypotheses that the gradient in the environmental conditions inside a marine cave would have a strong effect over the recruitment and successional patterns of the epifaunal community. Specifically, it would be expected that a higher degree of isolation toward the inner parts of the cave would negatively affect variables such as (1) number of species and their individual abundances and (2) the rate of development of the community. Additionally, it can be presumed that with longer periods available for colonization, there would be a convergence in the taxa present in each substrate (Berlow 1997). If artificial substrates deployed at external stations developed communities earlier, it could be expected that (3) inner stations will show a lower degree of community composition similarity.

\section{MATERIALS AND METHODS}

\section{Study site and experimental stations}

The experiment was carried out at Cerro Gordo cave, situated inside the Maro-Cerro Gordo Natural

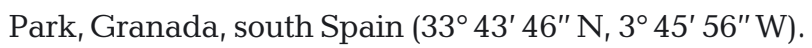
This region, located in the Alboran Sea, presents a highly diverse benthic community due to the special hydrographic conditions in this area, i.e. mixing of Mediterranean and Atlantic waters and the presence of upwelling currents (Delgado 1990, Cebrián et al. 2000). Cerro Gordo cave is a karstic and lineal cavity with several air chambers. At approx. $100 \mathrm{~m}$ long, it is one of the longest marine caves in southern Spain. Four stations (A-D), situated between 14 and $9 \mathrm{~m}$ depth, were established following a lengthwise gradient (Fig. 1). Stn A was situated in the external area (ca. $10 \mathrm{~m}$ outside the cave mouth), where the benthic community was mainly dominated by macroalgae. Stn B was situated in a large semi-dark hall (approx. $15 \mathrm{~m}$ width, $15 \mathrm{~m}$ high and $25 \mathrm{~m}$ long) with an air chamber at the top. In this area, the walls showed a rich community of sessile invertebrates including cnidarians (e.g. Astroides calycularis, Parazoanthus axinellae, Eudendrium sp.), sponges (Chondrosia reniformis, Ircinia sp.), bryozoans (Myriapora truncata, Pentapora fascialis) and sessile polychaetes (Salmacina dysteri). Twenty-five meters from the entrance there 


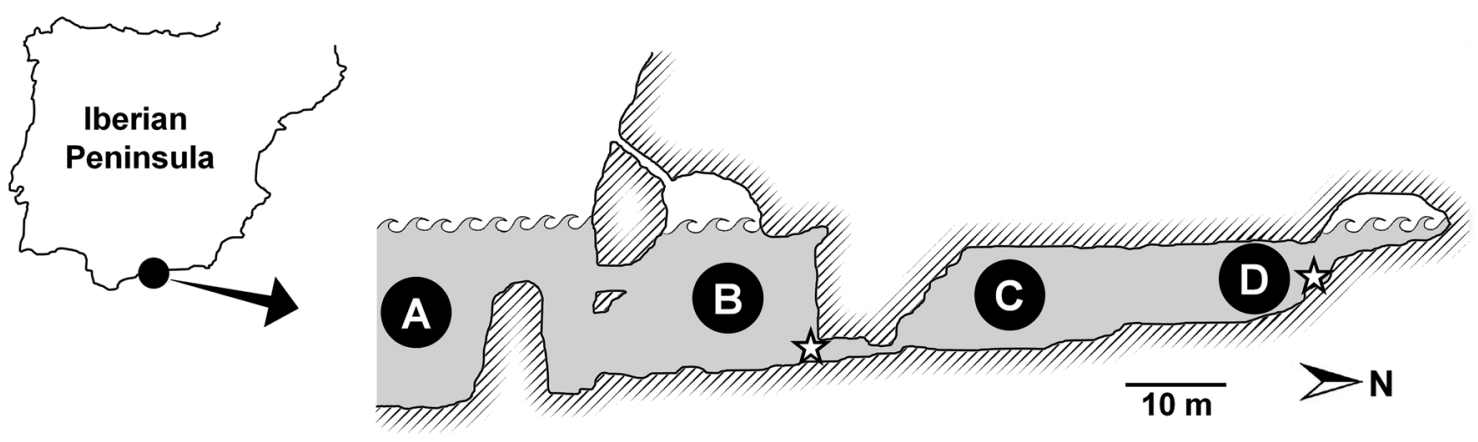

Fig. 1. Location and longitudinal section of Cerro Gordo cave, Spain, showing experimental Stns A-D (modified from NavarroBarranco et al. 2012). Stars indicate the approximate location of the 2 temperature data loggers

is a marked narrowing, which separates the semidark and completely dark areas of the cave. At Stn C, approx. $60 \mathrm{~m}$ from the cave entrance, the sessile community is composed mainly of encrusting sponges and brachiopods. Finally, at the last station (Stn D) situated near the end of the cave $(\sim 80 \mathrm{~m}$ from the entrance), the hard substrate is almost completely bare.

\section{Experimental design}

Twelve artificial epifaunal collectors were deployed at each station on 1 June 2011. Each artificial substrate was composed of a $30 \mathrm{~cm}$ rope surrounded by a $20 \times 20 \mathrm{~cm}$ mosquito net rolled and attached with a cable tie. Similar structures have been successfully used to culture amphipods and have been proved to host a rich and abundant epifaunal community, probably because of the shelter against predators provided by their complex 3-dimensional structure (Baeza-Rojano et al. 2013). At each station, all the new substrates were deployed in an area $<1 \mathrm{~m}^{2}$, fixing the end of the rope to the wall. Four collectors were retrieved from each station at 3 different times: 1.5, 3 and 6 mo. Using SCUBA equipment, each collector was carefully enveloped in a plastic bag to avoid the loss of organisms, and preserved in $70 \%$ ethanol. In the laboratory, the mosquito net roll was opened and washed through a $0.5 \mathrm{~mm}$ mesh sieve to collect the mobile fauna. All organisms were sorted into higher taxa (phylum and class) and counted. Finally, all crustaceans were also identified to species level using a binocular microscope.

Additionally, in the framework of a monitoring program of the thermal fluctuations within the cave, 2 temperature data loggers (iBCod 22L) were deployed at the cave entrance and at the end of the cave. The temperature was recorded every $2 \mathrm{~h}$ from 5 January to 12 November 2011.

\section{Statistical analyses}

Spatial and temporal variation in the crustacean assemblages was examined using a permutational multivariate analysis of variance (PERMANOVA) with 2 factors: position (Po) and time (Ti). Position was a fixed factor with 4 levels: Stns A, B, C and D. Time was also a fixed factor, orthogonal with position, with 3 levels: 1.5, 3 and 6 mo $(\mathrm{n}=4)$. Data were fourth-root transformed to reduce the importance of extreme values, and a similarity matrix was generated using the Bray-Curtis similarity index. Terms found to be significant in the full model were examined individually using appropriate pairwise comparisons. These comparisons were also useful to obtain the similarity values among replicates in each $\mathrm{Po} \times \mathrm{Ti}$ combination. A permutational analysis of multivariate dispersions (PERMDISP) was carried out to test differences in the variation of the crustacean community among positions. The similarity percentage procedure (SIMPER) was conducted to identify those species with higher contribution in characterizing and separating positions. Multivariate analyses were performed using the PRIMER v. $6+$ PERMANOVA package (Anderson et al. 2008).

Following the same 2 factor design, the influence of position and time in the abundance and number of crustacean species was explored using a 2-way analysis of variance (ANOVA). Prior to analysis, homogeneity of variance was checked using Cochran's test, and transformations were applied when necessary (Underwood 1997). When ANOVA indicated a significant difference for a given factor (at $\alpha=0.05$ ), the source of difference was identified using Student-Newman-Keuls (SNK) tests. Additional 1-way ANOVAs were carried out to test whether the temperature measurements during each month differed significantly between the outer and inner part of the cave. Univariate analyses were implemented using GMAV-5 (Underwood et al. 2002). 


\section{RESULTS}

\section{Temperature measurements}

Significant differences in the water temperature between the cave entrance and end were observed for most months: February $(F=17.97$; $<<0.001)$, May $(F=$ $12.96 ; \mathrm{p}<0.001)$, June $(F=78.98 ; \mathrm{p}<0.001)$, July $(F=$ 111.69; $\mathrm{p}<0.001)$, August $(F=102.63 ; \mathrm{p}<0.001)$, September $(F=155.63 ; \mathrm{p}<0.001)$, October $(F=16.36 ; \mathrm{p}<$ $0.001)$ and November $(F=187.30 ; \mathrm{p}<0.001)$. Mean temperature at the entrance of the cave was $0.8^{\circ} \mathrm{C}$ lower than at the innermost part. January had the coldest mean temperature at both stations $\left(14.9^{\circ} \mathrm{C}\right.$ at the entrance and $15.2^{\circ} \mathrm{C}$ at the end) and August was the warmest month $\left(22.1^{\circ} \mathrm{C}\right.$ at the entrance and $23.3^{\circ} \mathrm{C}$ at the end). Although the range of temperature during the whole year was similar at both stations, the standard deviation was lower at the cave end in all months (sometimes up to 2 or 3 -fold smaller). At all temporal scales, the temperature was much more stable in the inner part of the cave (Fig. 2a-c).

\section{Epifaunal composition}

Arthropoda was the most abundant phylum by far, comprising $96.68 \%$ of the total number of individuals, followed by Annelida $(1.74 \%)$, Mollusca $(1.21 \%)$ and Echinodermata (0.31\%). Arthropoda was the dominant group in all posi-
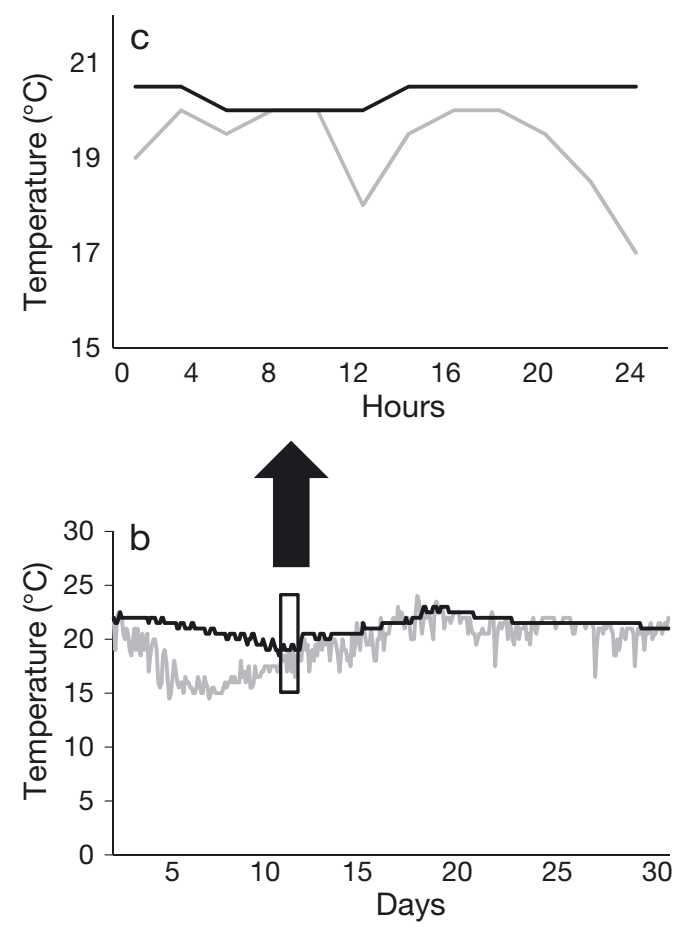

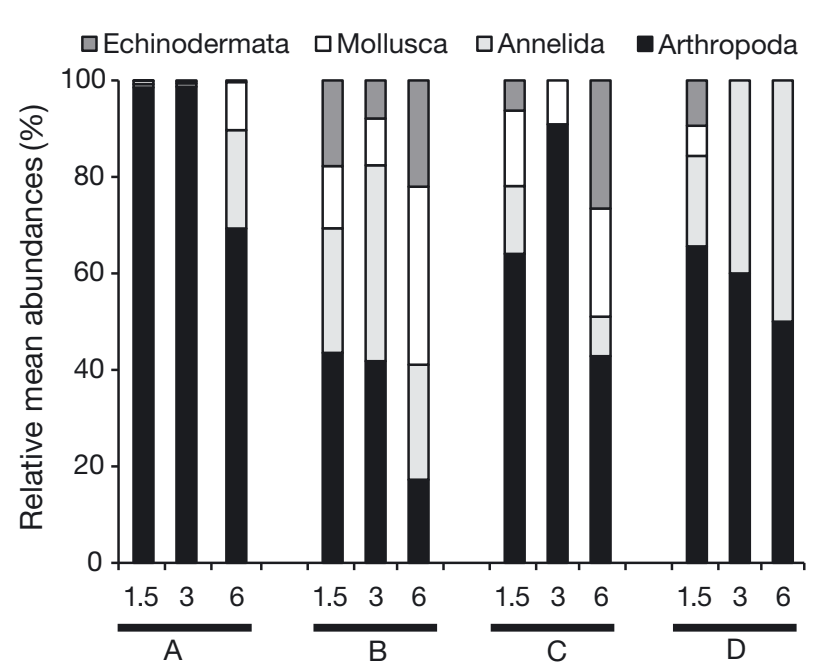

Fig. 3. Relative mean abundances (\%) of each phylum in

each cave position (Stns A, B, C and D) and sampling time $(1.5,3$ and $6 \mathrm{mo})$

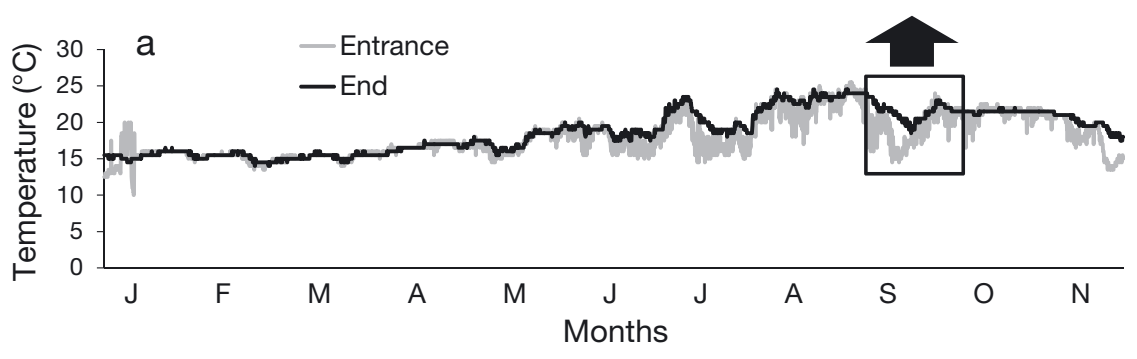

Fig. 2. Temperature measurements ( $2 \mathrm{~h}$ frequency) at the entrance and end of the cave over (a) 1 yr (2011), (b) 1 mo (September), and (c) 1 d (11 September) tions and times of colonization (with the exception of the semidark Stn B at 6 mo) (Fig. 3). All the individuals belonging to Annelida were polychaetes and, except for some pycnogonids, all arthropods were crustaceans (class Malacostraca). Mollusca specimens belonged to Bivalvia and Gastropoda. Within Echinodermata, there were both sea urchins and ophiuroids. Thirty-four crustacean species were found during the study: 17 amphipods, 8 decapods, 4 isopods, 3 tanaids and one cumacean species (Table 1). The gammarids Jassa slatteryi and Stenothoe tergestina were the most abundant species, being dominant at all stations. Other important species were Elasmopus rapax and Lembos websteri at the external station (Stn A), the caprellids Pseudoprotella phasma and Phtisica marina in the semidark area (Stn B), and Leptocheirus pectinatus and the decapods Eualus sp. and Athanas sp. in the 3 cave positions (Stns B, C and D). However, SIMPER 


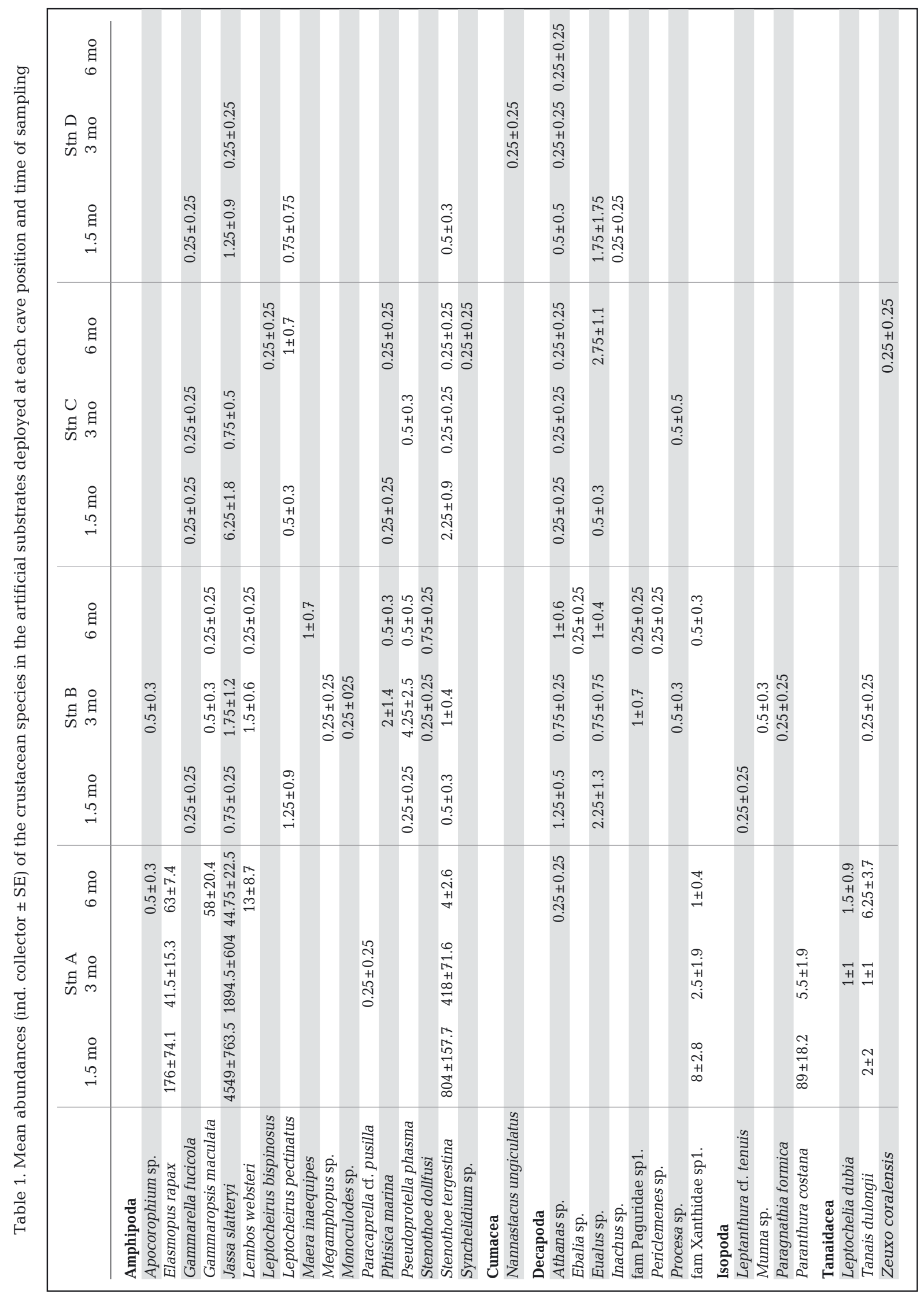


Table 2. Results of the multivariate analyse PERMANOVA for the crustacean community, based on Bray-Curtis similarities of fourth-root transformed data

\begin{tabular}{|lrccc|}
\hline Source of variation & df & MS & $F$ & $p$ \\
\hline Position (Po) & 3 & 1656 & 7.021 & $<0.001$ \\
Time (Ti) & 2 & 8148.1 & 3.462 & $<0.001$ \\
Po $\times$ Ti & 6 & 4591.8 & 1.951 & $<0.001$ \\
Residual & 36 & 2353.9 & & \\
\hline
\end{tabular}

Table 3. Multivariate pairwise comparison for interaction of factors position and time. (=) not significantly different; $(\neq)$ significantly different at $p<0.05$

Pairwise comparison among stations (A-D) within each time of sampling

$$
\begin{array}{cl}
1.5 \text { mo } & A \neq B=C=D \\
3 \text { mo } & A \neq B \neq C=D \\
6 \text { mo } & A \neq B \neq C \neq D
\end{array}
$$

Pairwise comparison among times of sampling (T1.5, T3, T6) within each station

$\begin{array}{ll}\text { Stn A } & \mathrm{T} 1.5 \neq \mathrm{T} 3 \neq \mathrm{T} 6 \\ \text { Stn B } & \mathrm{T} 1.5 \neq \mathrm{T} 3=\mathrm{T} 6 \\ \text { Stn C } & \mathrm{T} 1.5=\mathrm{T} 3 \neq \mathrm{T} 6 \\ \text { Stn D } & \mathrm{T} 1.5=\mathrm{T} 3=\mathrm{T} 6\end{array}$

results did not show important differences in the main species characterizing positions, because of the dominance of Jassa slatteryi and Stenothoe tergestina at all stations.

\section{Colonization and succession}

PERMANOVA highlighted the existence of a significant interaction between position and time $(\mathrm{Po} \times \mathrm{Ti})$, which indicates that differences among positions were not constant in time and nor were differences among times constant in space (Table 2). Pairwise comparisons among positions for each time point $(1.5,3$ and $6 \mathrm{mo}$ ) showed a progressive differentiation of the communities from the outer stations toward the inner part of the cave (Table 3). After $1.5 \mathrm{mo}$, only the artificial substrates deployed outside the cave (Stn A) showed a distinctive community that was significantly different from those present at all other stations, while no significant differences were observed among internal cave positions (Stns B, C and D). At $3 \mathrm{mo}$, the community in the semi-dark area (Stn B) had also developed a significantly differentiated structure (in contrast, Stns C and D still remained similar to each other). Finally, after $6 \mathrm{mo}$, each of the stations showed an exclusive and characteristic community. On the other hand, pairwise comparisons among levels of factor time for each position revealed that internal areas (Stns B, C and D) were much more stable environments than external ones (Table 3). Outside the cave (Stn A), significant variations were observed in the crustacean community among all sampling times, while there were no differences at the cave end (Stn D).

The univariate analysis for abundance and species richness also reflected a significant interaction between the factors position and time, and SNK analyses revealed similar trends to the previous pairwise comparisons (Tables 4 \& 5). Differentiation among stations increased over time. At the beginning of the experiment there were significant differences in the species richness only between Stns A and D. However, the divergences among stations gradually increased and became significant among all cave positions by the end of the study (with a decrease in

Table 4. Results of 2-way ANOVA for abundance and species richness values for the crustacean community. No transformation was necessary for species richness. Abundance data were $\ln (x+1)$ transformed

\begin{tabular}{|lrrrrrrrr|}
\hline \multirow{2}{*}{$\begin{array}{l}\text { Source of } \\
\text { variation }\end{array}$} & df & \multicolumn{4}{c}{ Abundance of organisms } & \multicolumn{3}{c|}{ Species richness } \\
& & & MS & \multicolumn{1}{c}{$F$} & $\mathrm{p}$ & $\mathrm{MS}$ & $F$ & $\mathrm{p}$ \\
\hline Position (Po) & 3 & 99.12 & 265.61 & $<0.001$ & 66.24 & 28.14 & $<0.001$ \\
Time (Ti) & 2 & 6.41 & 17.17 & $<0.001$ & 0.53 & 0.22 & 0.803 \\
Po $\times$ Ti & 6 & 3.27 & 8.81 & $<0.001$ & 11.99 & 5.09 & 0.001 \\
Residual & 36 & 0.37 & & & 2.35 & & \\
\hline
\end{tabular}

Table 5. Pairwise comparisons for the interaction of factors position and time in

\begin{tabular}{|c|c|c|c|}
\hline \multicolumn{2}{|c|}{ Number of individuals } & \multicolumn{2}{|c|}{ Species richness } \\
\hline \multicolumn{4}{|c|}{ Pairwise comparison among stations (A-D) within each time of sampling } \\
\hline T1.5 mo & $\mathrm{A} \neq \mathrm{B}=\mathrm{C}=\mathrm{D}$ & $\mathrm{T} 1.5 \mathrm{mo}$ & $\mathrm{A}=\mathrm{B}=\mathrm{C}=\mathrm{D} ; \mathrm{A} \neq \mathrm{D}$ \\
\hline T3 mo & $\mathrm{A} \neq \mathrm{B}=\mathrm{C}=\mathrm{D}$ & T3 mo & $\mathrm{A} \neq \mathrm{B} \neq \mathrm{C}=\mathrm{D}$ \\
\hline T6 mo & $A \neq B=C \neq D$ & T6 mo & $A \neq B \neq C \neq D$ \\
\hline \multicolumn{4}{|c|}{ Pairwise comparison among times of sampling $(\mathrm{T} 1.5, \mathrm{~T} 3, \mathrm{~T} 6)$ within each statior } \\
\hline Stn A & $\mathrm{T} 1.5 \neq \mathrm{T} 3 \neq \mathrm{T} 6$ & Stn A & $\mathrm{T} 1.5=\mathrm{T} 3 \neq \mathrm{T} 6$ \\
\hline Stn B & $\mathrm{T} 1.5=\mathrm{T} 3=\mathrm{T} 6$ & Stn B & $\mathrm{T} 3 \neq \mathrm{T} 1.5=\mathrm{T} 6$ \\
\hline Stn C & $\mathrm{T} 1.5=\mathrm{T} 3=\mathrm{T} 6$ & Stn C & $\mathrm{T} 1.5=\mathrm{T} 3=\mathrm{T} 6$ \\
\hline Stn D & $\mathrm{T} 1.5=\mathrm{T} 3=\mathrm{T} 6$ & Stn D & $\mathrm{T} 1.5=\mathrm{T} 3=\mathrm{T} 6$ \\
\hline
\end{tabular}
abundance and species richness values. $(=)$ not significantly different; $(\neq)$ significantly different at $p<0.05$ 

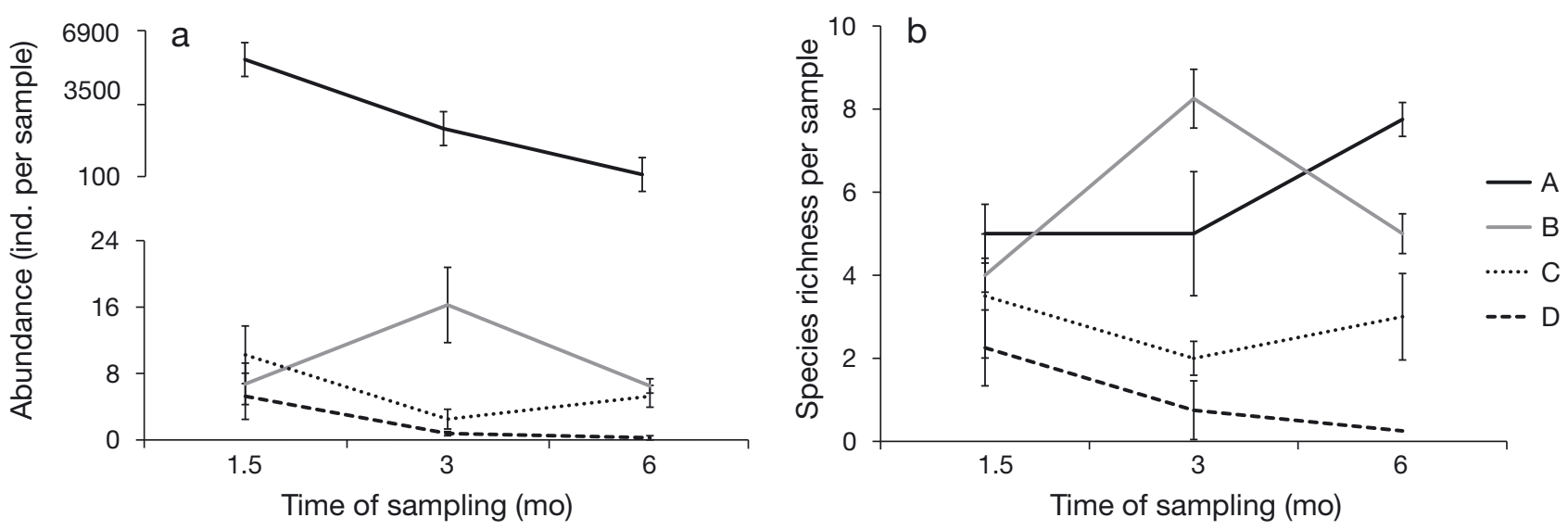

Fig. 4. Mean values $\pm \mathrm{SE}$ of (a) total abundance and (b) species richness for each station and sampling time

the number of species toward the inner part of the cave) (Fig. 4b). Abundance values were significantly higher at Stn A throughout the whole study (Fig. 4a). Nevertheless, no significant differences in the number of individuals were observed among cave areas (Stns B, C and D), except for Stns C and D at 6 mo.

With regard to the temporal changes within each station, univariate analysis also revealed higher stability at internal stations. Only the external Stn A showed significant changes, with an increase in the number of species (mainly due to the occurrence of Gammaropsis maculata and Lembos websteri at $6 \mathrm{mo}$ ) and a significant decrease in the number of individuals at 3 and $6 \mathrm{mo}$. In contrast, no significant differences in abundance and species richness were detected at internal Stns B, C and D. The only exception was a peak in the number of species at the semidark Stn B at 3 mo, which was caused by a higher frequency of occurrence of the species present in the replicates and not by the arrival of new species.

PERMDISP results indicated significant variation among positions (stations). Similarity values obtained for each position reflected a decrease in homogeneity among replicates toward the inner parts of the cave; $81.4 \%$ at Stn A, $35.9 \%$ at Stn B, $34.4 \%$ at Stn C and $4.9 \%$ at Stn D. No tendency toward convergence among replicates within stations was observed over time.

\section{DISCUSSION}

\section{Epifaunal composition}

The dominance of crustaceans is a common feature of epifaunal communities, including in marine caves (Taylor 1997, Navarro-Barranco et al. 2014 and refer- ences therein). However, none of the 34 species found in this study were cave-exclusive. Many of the species collected are not specialized for subterranean life (i.e. they have a wide ecological niche), which is a common feature in marine cave fauna (Scipione et al. 1981, Gerovasileiou \& Voultsiadou 2012, NavarroBarranco et al. 2013). The overwhelming dominance of genus Jassa observed in the deployed substrates has been previously reported in other artificial habitats (Beermann \& Franke 2012). This genus shows a great dispersal capability (mainly via drifting juveniles), which explains its presence at all stations and its especially high abundance on the exposed substrates (Havermans et al. 2007, Beermann \& Franke 2012). Many taxa were found as singletons and/or with densities $<1$ per replicate. Some of them were soft-bottom species (such as Monoculodes sp. and Synchelidium sp.), whose occurrence in our artificial substrates could be considered accidental. The occurrence of a caprellid species belonging to the genus Paracaprella, a common taxa in subtropical and tropical seas around the world but virtually absent in Mediterranean waters, is of note. The species collected probably belongs to the only Paracaprella species found in the Mediterranean, $P$. pusilla, which was recently cited as a new exotic species in these waters but until now only found among the fouling communities in harbours (Ros \& GuerraGarcía 2012, Ros et al. 2013).

\section{Recruitment and successional patterns}

As expected, there was a significant decrease both in species richness and abundance on the artificial substrates toward the inner part of the cave. The main processes commonly used to explain epifaunal 
distribution patterns are related to (1) selection of favored substrates, (2) variations in the arrival of recruits and (3) differences in species' abilities to cope with the ecological conditions they are exposed to (Beermann \& Franke 2012, Vázquez-Luis et al. 2012). The host substrate was the same at all positions, so we can exclude this factor as a responsible agent of the observed differences. Since our temperature data show that the water exchange in the cave is limited, it could be expected that these patterns were due to the inability of the organisms to colonize the inner parts of the cave. Laboratory experiments carried out with grazing isopods and amphipods highlighted that propagule supply can play an important role (even higher than resource limitation) in structuring the community (Lee \& Bruno 2014). However, the dominant crustacean species outside the cave, regardless of their development mode (direct or indirect), were also present in all the internal positions from the first sampling time. Although we cannot conclusively demonstrate that these recruits are coming from outside the cave (as they could come from nearby areas via short-distance dispersal events), these results would agree with some previous studies highlighting that water movement is often enough for propagules to reach the innermost part of a cave, in contrast to traditional expectations (Denitto et al. 2007, Moscatello \& Belmonte 2007). In spite of being present at internal stations from the beginning of the experiment, the abundances of the dominant species were much lower progressing into the cave, throughout the whole study. Thus, differences in abundance across positions probably depended on changes in the environmental conditions (e.g. trophic supply, light intensity and rate of water exchange) rather than a limitation in the number of propagules that reached and colonized the inner part of the cave.

Our results also confirm that a gradient in the rate of development along cave environments may also be applied to mobile epifauna communities. The lower rate of development is a feature traditionally associated with marine cave communities but still poorly studied. Previous studies using sessile benthic communities have highlighted that the time required for colonization and development is much longer in marine caves than in open habitats (Denitto et al. 2007). Harmelin (1985) observed that, even after 9 yr, the bryozoan community inside a marine cave was still far from reaching the natural richness in the adjacent non-defaunated walls. The timescale in the present study is considerably longer than that usually considered in epifaunal colonization studies (with a time scale of days or weeks), but our observations indicate that such a relatively long time scale is necessary to understand the development of cave communities (Poore 2005, Roberts \& Poore 2006, GuerraGarcía \& García-Gómez 2006). Although the external station (Stn A) showed significant differences in abundances, species richness, and structure after 1.5 mo (in comparison with those artificial substrates deployed inside the cave), it took 6 mo for these same metrics to have differences between Stns C and D.

The lower rate of successional changes inside the cave is also visible in the higher temporal stability of these communities. Both multivariate and univariate analyses showed similar temporal patterns for cave stations, whereas the epifaunal community outside the cave showed higher temporal variability. While the innermost station (Stn D) exhibited similar assemblage structure, number of species and abundance values during the entire study, these variables showed significant differences among times of sampling outside the cave. In this sense, the dampening of thermal oscillations within the cave observed here, and also reported in other Mediterranean marine and anchialine caves (Harmelin 1997, Novosel et al. 2007), could be a responsible factor for the stability of cave communities. The significant decrease in the number of species at 3 and 6 mo in the external position probably was due to the decrease in the water temperature from summer to winter (Nakaoka et al. 2001, Guerra-García et al. 2011, Beermann 2014). Along with temperature, there are many other factors (e.g. wave exposure, light conditions, trophic supply and coverage of host substrates) in which variations will be more pronounced outside the cave and that could explain these differences in the temporal stability.

\section{Spatial and temporal variations in the small-scale variability}

Although small-scale variability is a general property of benthic assemblages in marine coastal environments, its importance can change among different habitats (Fraschetti et al. 2005). In the case of marine cave benthic communities, they are often characterized by a high small-scale patchiness (Benedetti-Cecchi et al. 1997, 1998, Martí et al. 2004), which agrees with our observations that artificial substrates inside the cave showed higher smallscale variability. A possible explanation could be related to differences in isolation conditions, since substrates with a higher supply of colonizers host more homogeneous epifauna (Lee \& Bruno 2014). 
However, Denitto et al. (2007) suggested that such small-scale variability in cave communities does not derive from a patchy colonization, but from other post-settlement factors. There are many biological interactions and physical processes that may generate large spatial variance at a scale of meters or even centimeters (Benedetti-Cecchi 2001, Fraschetti et al. 2005 and references therein). The low densities of individuals could also contribute to this high heterogeneity inside caves, since the movement of epifauna among habitat patches is often positively related to the density within patches (Holmquist 1998, Tanaka \& Leite 2004). In this sense, the dense aggregations of individuals in external collectors may determine higher dispersal movement, which favors a higher convergence in the species present in each collector.

With regard to the temporal variation of the smallscale variability, Berlow (1997) proposed several successional models for benthic communities, each of which had different predictions. According to the contingent succession and the canalized succession model, biological interactions are very important in the successional pathway and so variability should be lower with increasing stages of succession. However, the high heterogeneity among collectors observed inside the cave throughout our study fits better with an externally-driven succession model, in which the successional variation is driven mainly by stochastic variations in the environmental conditions, instead of biological interactions.

Although the observed patterns are quite similar to those initially expected for marine caves, we must be cautious about drawing general conclusions. Chapman (2007) found it difficult to obtain general and predictable patterns in the invertebrate species composition and community structure in the colonization of novel intertidal and shallow subtidal habitats. Moreover, a common feature of marine caves is the difficulty to find general patterns (Bussotti et al. 2006, Navarro-Barranco et al. 2013), since the hydrodynamics (and so the isolation conditions) are highly variable among marine caves in function of orientation, depth and topography.

\section{CONCLUSIONS}

The present study highlights the presence of a gradient in the mobile epifauna community inhabiting marine caves. The changes in the environmental conditions along the length of the cave likely determine significant differences in the assemblage structure, their small-scale variability, temporal stability and rate of development. Stations located within the cave showed lower abundance and species richness values compared to the external station. This community impoverishment should be attributed to factors such as the decrease in the trophic supply, rather than to a limitation in the ability of propagules to reach the internal part of the caves. The small rate of change and slow succession observed here could be considered a signal of the sensitivity of these habitats, and hence the importance of their conservation. The challenge for future studies is to quantify the resilience capacity of cave communities to specific natural and human disturbances, which is expected to assist management and conservation actions.

Acknowledgements. Financial support for this work was provided by the Ministerio de Economía y Competitividad (Project CGL 2011-22474, internal reference 2011-707) cofinanced by FEDER funds of the European Union, and by the Consejería de Economía, Innovación, Ciencia y Empleo, Junta de Andalucía (Project P11-RNM-7041). We are grateful to Carlos González for collaboration in field sampling and Dr. Sophie McCoy, who conducted the English revision of the manuscript. Special thanks to Sara Cea and Pablo Jiménez-Prada for help sorting the organisms, and to Dr. Vasilis Gerovasileiou and to anonymous reviewers for their helpful comments. This work forms part of C.N.-B.'s PhD thesis, supported by the University of Seville (PIF Grant).

\section{LITERATURE CITED}

Anderson MJ, Gorley RN, Clarke KR (2008) PERMANOVA+ for PRIMER: guide to software and statistical methods. PRIMER-E, Plymouth

Antoniadou C, Voultsiadou E, Chintiroglou C (2010) Benthic colonization and sucession on temperate sublittoral rocky cliffs. J Exp Mar Biol Ecol 382:145-153

Baeza-Rojano E, Calero-Cano S, Hachero-Cruzado I, Guerra-García JM (2013) A preliminary study of the Caprella scaura amphipod culture for potential use in aquaculture. J Sea Res 83:146-151

Beermann J (2014) Spatial and seasonal population dynamics of sympatric Jassa species (Crustacea; Amphipoda). J Exp Mar Biol Ecol 459:8-16

Beermann J, Franke HD (2012) Differences in resource utilization and behaviour between coexisting Jassa species (Crustacea, Amphipoda). Mar Biol 159:951-957

Benedetti-Cecchi L, Airoldi L, Abbiati M, Cinelli F (1997) Exploring the causes of spatial variation in an assemblage of benthic invertebrates from a submarine cave with sulphur springs. J Exp Mar Biol Ecol 208:153-168

> Benedetti-Cecchi L, Airoldi L, Abbiati M, Cinelli F (1998) Spatial variability in the distribution of sponges and cnidarians in a sublittoral marine cave with sulphurwater springs. J Mar Biol Assoc UK 78:43-58

Benedetti-Cecchi L (2001) Variability in abundance of algae and invertebrates at different spatial scales on rocky sea shores. Mar Ecol Prog Ser 215:79-92

> Berlow EL (1997) From canalization to contingency: historical effects in a successional rocky intertidal community. Ecol Monogr 67:435-460 
Bussotti S, Terlizzi A, Fraschetti S, Belmonte G, Boero F (2006) Spatial and temporal variability of sessile benthos in shallow Mediterranean marine caves. Mar Ecol Prog Ser 325:109-119

$>$ Cebrián E, Ballesteros E, Canals M (2000) Shallow rocky bottom benthic assemblages as calcium carbonate producers in the Alboran Sea (southwestern Mediterranean). Oceanol Acta 23:311-322

Chapman MG (2007) Colonization of novel habitat: test of generality of patterns in a diverse invertebrate assemblage. J Exp Mar Biol Ecol 348:97-110

Delgado M (1990) Phytoplankton distribution along the Spanish coast of the Alboran Sea. Sci Mar 54:169-178

> Denitto F, Terlizzi A, Belmonte G (2007) Settlement and primary succession in a shallow submarine cave: spatial and temporal benthic assemblage distinctness. Mar Ecol 28:35-46

Eggleston DB, Ward EE, Etherington LL, Dahlgren CP, Posey MH (1999) Organism responses to habitat fragmentation and diversity: habitat colonization by estuarine macrofauna. J Exp Mar Biol Ecol 236:107-132

- Fraschetti S, Giangrande A, Terlizzi A, Boero F (2002) Preand post-settlement events in benthic community dynamics. Oceanol Acta 25:285-295

Fraschetti S, Terlizzi A, Benedetti-Cecchi L (2005) Patterns of distribution of marine assemblages from rocky shores: evidence of relevant scales of variation. Mar Ecol Prog Ser 296:13-29

García-Sanz S, Tuya F, Navarro PG, Angulo-Preckler C, Haroun RJ (2012) Post larval, short term, colonization patterns: The effect of substratum complexity across subtidal, adjacent, habitats. Estuar Coast Shelf Sci 112: 183-191

Gerovasileiou V, Voultsiadou E (2012) Marine caves of the Mediterranean Sea: a sponge biodiversity reservoir within a biodiversity hotspot. PLoS ONE 7:e39873

Guerra-García JM, García-Gómez JC (2006) Recolonization of defaunated sediments: fine versus gross sand and dredging versus experimental trays. Estuar Coast Shelf Sci 68:328-342

- Guerra-García JM, Baeza-Rojano E, Cabezas MP, GarcíaGómez JC (2011) Vertical distribution and seasonality of peracarid crustaceans associated with intertidal macroalgae. J Sea Res 65:256-264

Harmelin JG (1985) Bryozoan dominated assemblages in Mediterranean cryptic environments. In: Nielsen C, Larwood GP (eds) Bryozoans: Ordovician to present. Olsen \& Olsen, Fredensborg, p 135-364

Harmelin JG (1997) Diversity of bryozoans in a Mediterranean sublittoral cave with bathyal-like conditions: role of dispersal processes and local factors. Mar Ecol Prog Ser 153:139-152

> Havermans C, De Broyer C, Mallefet J, Zintzen V (2007) Dispersal mechanisms in amphipods: a case study of Jassa herdmani (Crustacea, Amphipoda) in the North Sea. Mar Biol 153:83-89

Holmquist JG (1998) Permeability of patch boundaries to benthic invertebrates: influences of boundary contrast, light level, and faunal density and mobility. Oikos 81: 558-566

> Lee SC, Bruno JF (2014) Propagule supply limits grazer richness equally across a resource gradient. Ecosphere 5:art8

> Martí R, Uriz JM, Ballesteros E, Turon X (2004) Temporal variation of several structure descriptors in animaldominated benthic communities in two Mediterranean caves. J Mar Biol Assoc UK 84:573-580

Moscatello S, Belmonte G (2007) The plankton of a shallow submarine cave ('Grotta di Ciolo' Salento Peninsula, SE Italy). Mar Ecol 28:47-59

Nakaoka M, Toyohara T, Matsumasa M (2001) Seasonal and between-substrate variation in mobile epifaunal community in a multispecific seagrass bed of Otsuchi Bay, Japan. Mar Ecol 22:379-395

Navarro-Barranco C, Guerra-García JM, Sánchez-Tocino L, García-Gómez JC (2012) Soft-bottom crustacean assemblages in Mediterranean marine caves: the cave of Cerro Gordo (Granada, Spain) as case study. Helgol Mar Res 66:567-576

- Navarro-Barranco C, Guerra-García JM, Sánchez-Tocino L, Jiménez-Prada P, Cea S, García-Gómez JC (2013) Softbottom diversity patterns in marine caves; lessons from crustacean community. J Exp Mar Biol Ecol 446:22-28

Navarro-Barranco C, Guerra-García JM, Sánchez-Tocino L, García-Gómez JC (2014) Mobile epifaunal community in marine caves in comparison to open habitats. Aquat Biol 20:101-109

- Novosel M, Jalži B, Novosel A, Pasari M, Požar-Domac A, Radi I (2007) Ecology of an anchialine cave in the Adriatic Sea with special reference to its termal regime. Mar Ecol 28:3-9

Olabarria C (2002) Role of colonization in spatio-temporal patchiness of microgastropods in coralline turf habitat. J Exp Mar Biol Ecol 274:121-140

Pacheco AS, Laudien J, Thiel M, Oliva M, Arntz W (2010) Succession and seasonal variation in the development of subtidal macrobenthic soft bottom communities off northern Chile. J Sea Res 64:180-189

> Poore AGB (2005) Scales of dispersal among hosts in a herbivorous marine amphipod. Austral Ecol 30:219-228

> Roberts DA, Poore AGB (2006) Habitat configuration affects colonisation of epifauna in a marine algal bed. Biol Conserv 127:18-26

> Ros M, Guerra-García JM (2012) On the ocurrence of the tropical caprellid Paracaprella pusilla Mayer 1890 (Crustacea: Amphipoda) in Europe. Mediterr Mar Sci 13: 134-139

Ros M, Vázquez-Luis M, Guerra-García JM (2013) The tropical caprellid amphipod Paracaprella pusilla: a new alien crustacean in the Mediterranean Sea. Helgol Mar Res 67: $675-685$

Scipione MB, Taramelli E, Fresi E, Cinelli F, Mazzella L (1981) Distribuzione delle biocenosi bentoniche lungo un gradiente di luce in una grotta marina superficiale: Anfipodi. Mem Biol Mar Oceanogr 11:1-16

> Sutherland JP (1974) Multiple stable points in natural communities. Am Nat 108:859-873

> Tanaka MO, Leite PP (2004) Distance effects on short-term recolonization of Sargassum stenophyllum by mobile epifauna, with an analysis of gammarid life habits. J Mar Biol Assoc UK 84:901-910

Taylor RB (1997) The role of small mobile spifauna in subtidal rocky reef ecosystems. PhD thesis, University of Auckland

Taylor RB (1998) Short-term dynamics of a seaweed epifaunal assemblage. J Exp Mar Biol Ecol 227:67-82

Thiel M (2003) Rafting of benthic macrofauna: important factors determining the temporal succession of the assemblage on detached macroalgae. Hydrobiologia 503:49-57

Tuya F, Wernberg T, Thomsen MS (2009) Colonization of 
gastropods on subtidal reefs depend on density in adjacent habitats, not on disturbance regime. J Molluscan Stud 75:27-33

Underwood AJ (1997) Experiments in ecology: their logical design and interpretation using analysis of variance. Cambridge University Press, Cambridge

Underwood AJ, Chapman MG (2006) Early development of subtidal macrofauna assemblages: relationships to period and timing of colonization. J Exp Mar Biol Ecol 330:221-233

Underwood AJ, Chapman MG, Richards SA (2002) GMAV5 for Windows: an analysis of variance programme. University of Sydney

Vázquez-Luis M, Borg JA, Sánchez-Jerez P, Bayle-Sempere

Editorial responsibility: Romuald Lipcius,

Gloucester Point, Virginia, USA
JT (2012) Habitat colonization by amphipods: comparison between native and alien algae. J Exp Mar Biol Ecol 432-433:162-170

Virnstein RW, Curran MC (1986) Colonization of artificial seagrass versus time and distance from source. Mar Ecol Prog Ser 29:279-288

Zabala M, Riera T, Gili JM, Barange M, Lobo A, Peñuelas J (1989) Water flow, trophic depletion, and benthic macrofauna impoversihment in a submarine cave from the western Mediterranean. Mar Ecol 10:271-287

Zajac RN, Whitlatch RB, Thrush SF (1998) Recolonization and succession in soft-sediment infaunal communities: the spatial scale of controlling factors. Hydrobiologia 375/376:227-240

Submitted: May 20, 2014; Accepted: November 17, 2014 Proofs received from author(s): January 26, 2015 